\title{
Application of in-line polymer addition for tailings disposal-learning and challenges part II
}

\author{
Raymond Guang Golder Associates Ltd, Canada
}

Sue Longo Golder Associates Ltd, Canada

\begin{abstract}
The use of polyacrylamide-based high-molecular-weight polymer addition at the tailings storage facility (TSF) discharge locations has gained considerable interest in recent years. The intended result of implementing this technique is to have tailings slurry release clear water and create a steepened beach, compared to a conventional tailings slurry disposal method. This paper will focus on a study of a typical iron ore project which required improved water recovery.

It has been suggested in previous studies that un-even shear on the polymer dosed tailings deposition on the tailings beach may be problematic. In this testing program, tailings and polymer mixture were tested for water release behaviour under partially sheared and fully sheared conditions. It is concluded that varying the shear regime affects the initial water recovery, up to around two hours after mixing and shearing. At the end of the test, the shear regime had less effect on the overall water recovery.

A trade-off comparison between conventional slurry surface disposal and in-line polymer addition disposal is also presented in the paper. The trade-off study demonstrates that the in-line polymer addition technology could provide financial water-saving benefit.
\end{abstract}

\section{$1 \quad$ Background}

In Australia, like in many other part of the world, the cost of water for mining operations continues to increase. For the mine site mentioned in this paper, their cost of water was approximately $A \$ 3.50$ dollars per $\mathrm{m}^{3}$, which they obtained from reverse osmosis. Due to this high cost of water, the site was looking for a dewatering solution that could recover as much water as practicable, but with minimal capital cost. In the early stages of the project, in-line polymer addition was chosen as the most appropriate tailings management method. The intent of adding the polymer was to increase the recovery of water from the TSF to the processing plant through accelerating water release from the slurry after deposition while minimal capital expenditure.

In Guang et al. (2014) the initial polymer selection testwork was presented. Since then, this mine site began using in-line polymer addition at their TSF.

After the commissioning of the in-line polymer addition system, there are two expansions planned:

- Future expansion, looking at increasing the magnetite stream from 324 to $921 \mathrm{t} / \mathrm{h}$ with the HEM tailings stream added as well at $120 \mathrm{t} / \mathrm{h}$.

- Increase the magnetite thickener throughput from 200 to $324 \mathrm{t} / \mathrm{h}$. The additional throughput required increased water supply and they aimed to complete the expansion via a series of small-scale plant optimization projects and small capital investments in order to improve water recovery. One of the optimization projects involved balancing thickener underflow density with increased thickener throughput whilst still obtaining rapid water recovery benefits offered by in-line polymer addition 
at the TSF.

For the first part of the paper, an options assessment is presented (based on block 4 event in Figure 1). The purpose of the options assessment is to identify the preferred option for the management of tailings for the expansion of the processing capacity at the mine until the year 2035. It is also to assess if the existing in-line polymer tailings management system could be used for the future expansion.

A testwork program (based on block 6 event in Figure 1) was conducted on the in-line polymer addition process for magnetite tailings stream to see what the impact was of increased throughput on the polymer induced water recovery performance. The testing was also to provide information to conduct a cost-benefit analysis for the continued use of in-line polymer addition application at the higher throughput rate of $324 \mathrm{t} / \mathrm{h}$ and eventually $921 \mathrm{t} / \mathrm{h}$. In the second part of the paper, the results of the test work program are presented.

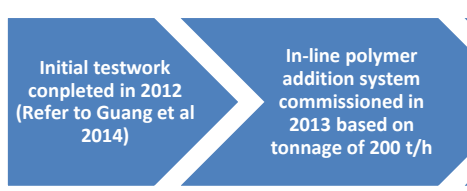

1

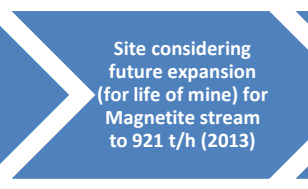

3

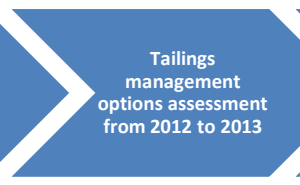

4

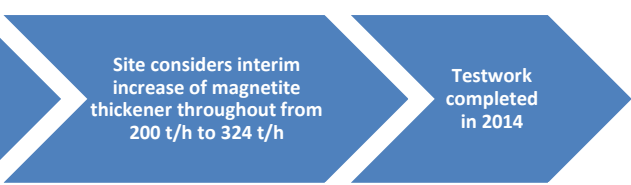

5

6

Figure 1 Brief project timeline

\section{Tailings information}

Tailings are generated from two different process streams at the processing plant; a hematite (HEM) and a magnetite (Mag) process stream. The particle size distributions of the tailings are presented in Figure 2 . As shown in the graph, the hematite (HEM) sample is finer than the magnetite sample. The combined sample is similar to the magnetite sample in terms of the particle size distribution.

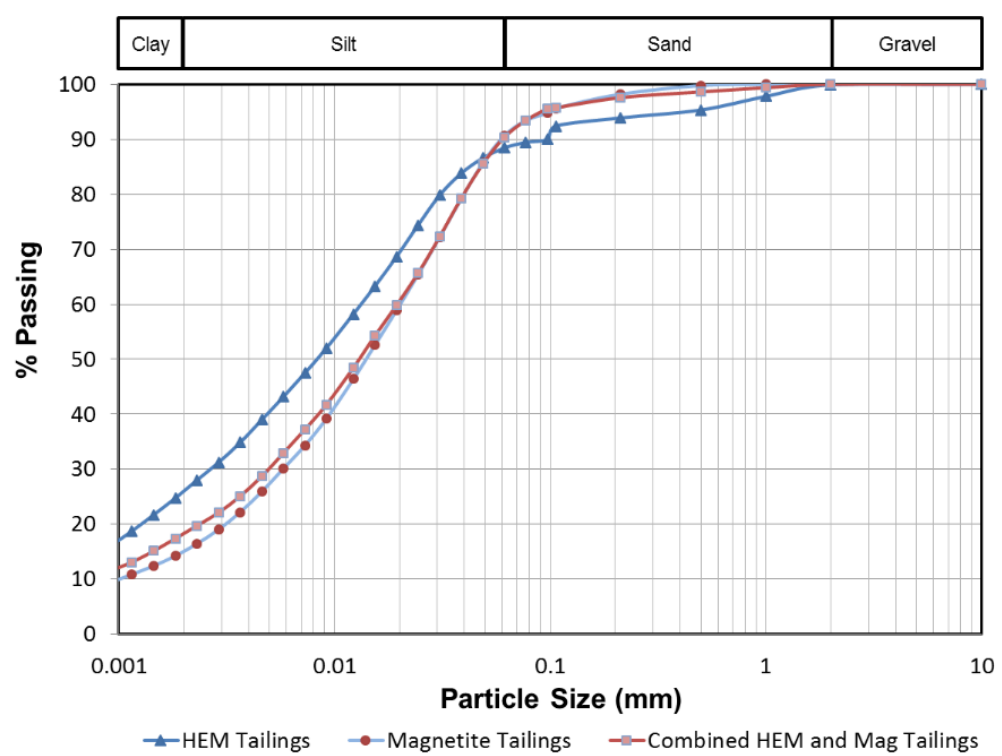

Figure 2 Particle size distribution for both tailings streams

The following tailings parameters have been used for this study. 


\begin{tabular}{ccc}
\hline Material & $\begin{array}{c}\text { Thickener underflow Solids concentration } \\
\text { (w/w solids) }\end{array}$ & $\begin{array}{c}\text { Specific } \\
\text { gravity }\end{array}$ \\
\hline HEM tailings & $38 \%$ & 3.35 \\
Magnetite tailings & $52 \%$ & 2.94 \\
Combined tailings stream (ratio of 3.2:1 Magnetite & $48 \%$ & 3.07 \\
to HEM tailings) & & \\
\hline
\end{tabular}

\section{Option study phase}

The purpose of this option study is to select a preferred concept for the management of tailings until the end of ore processing in 2035. There are two expansions planned:

- Future expansion, looking at increasing the magnetite stream from 324 to $921 \mathrm{t} / \mathrm{h}$ with the HEM tailings stream added as well at $120 \mathrm{t} / \mathrm{h}$.

- Ramping up magnetite thickener from 200 324 t/h.

\subsection{Management concepts}

Three concepts were identified for storing the life of mine (LOM) tailings. The concepts are described below:

- Concept 1-Deposition into existing TSF (surface disposal) and an additional cell.

- In order to accommodate the life of mine tailings production, an additional cell will need to be constructed. The aim of constructing the new cell would be to reduce the rate of rise on the existing TSF.

- Both tailings streams (Magnetite tailings and HEM tailings) will be transported via the underflow pumps to a mixing tank for thorough mixing. Then the combined tailings will be pumped by centrifugal pumps for perimeter discharge.

- Concept 2-In-line polymer addition to create a steepened beach profile.

- Similar to Concept 1 , both tailings streams will be transported via the underflow pumps to a mixing tank for thorough mixing. The tailings will be pumped by centrifugal pumps to a different location which is approximately $4 \mathrm{~km}$ away from the thickening plant (see Figure 3).

- At the point of discharge, tailings will be injected with polymer. A multiple spigot discharge scheme will be implemented to control tailings flow velocity, discharge energy and beach slope.

- Concept 3-Dry stack filtered tailings.

- Tailings will be dewatered using a filter press and trucked to the TSF for placement. In order to accommodate of the life of mine tailings, three dry stack sites will be required. The stacks would be required to be raised to a maximum height of approximately $66 \mathrm{~m}$ above natural surface level.

- As the tailings are progressively placed, a dozer would be used to spread and compact the tailings to form a trafficable working surface for the dump trucks. This will facilitate the stacking of further tailings in subsequent lifts.

The relative location and size of the TSFs for above concepts is shown below: 


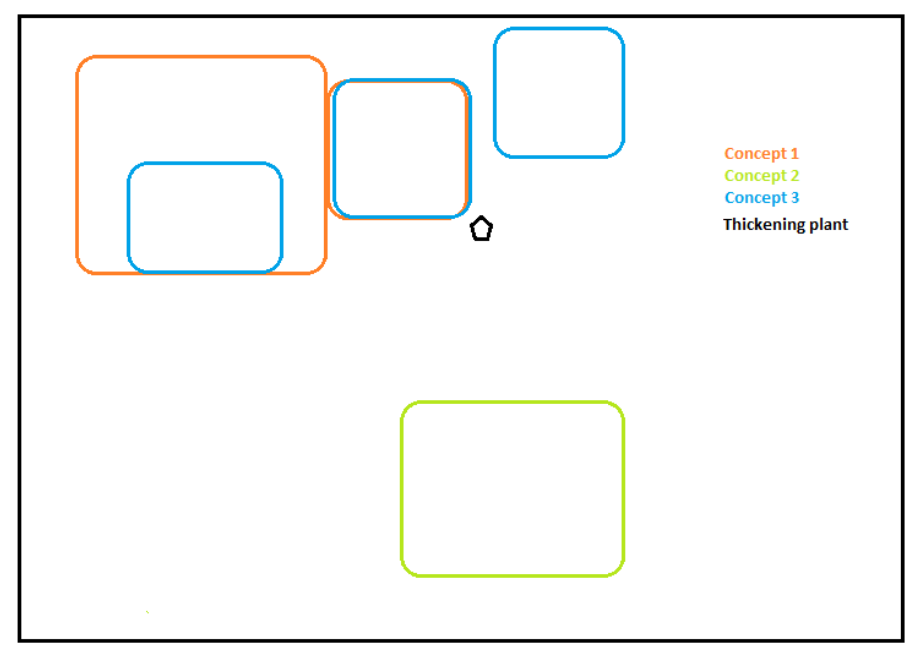

Figure 3 TSF location and size for three different concepts

The table below shows a summary of the cost estimates for the options considered above. The civil capital cost includes the earthworks required to construct the TSF. The process capital cost includes major mechanical equipment cost, mechanical installation, electrical installation, instrumentation installation, EPCM and contingency cost. The cost estimate has been prepared to target a nominal accuracy of approximately $+/-50 \%$ and should be considered a relative comparison of the options only.

Table 2 Cost estimate summary

\begin{tabular}{ccccc}
\hline $\begin{array}{c}\text { Option } \\
\text { description }\end{array}$ & $\begin{array}{c}\text { Initial Capital Cost } \\
\text { (Civil) }\end{array}$ & $\begin{array}{c}\text { Initial Capital Cost } \\
\text { (Process) }\end{array}$ & $\begin{array}{c}\text { Operating Cost } \\
\text { (Per year) }\end{array}$ & $\begin{array}{c}\text { Estimated Total } \\
\text { Cost }\end{array}$ \\
\hline Concept 1 & $\mathrm{A} \$ 34 \mathrm{M}$ & $\mathrm{A} \$ 14 \mathrm{M}$ & $\mathrm{A} \$ 2.5 \mathrm{M}$ & $\mathrm{A} \$ 244 \mathrm{M}$ \\
Concept 2 & $\mathrm{A} \$ 28 \mathrm{M}$ & $\mathrm{A} \$ 13 \mathrm{M}$ & $\mathrm{A} \$ 15.2 \mathrm{M}$ & $\mathrm{A} \$ 517 \mathrm{M}$ \\
\hline
\end{tabular}

Based on the cost estimate, Concept 3-Dry stack filtered tailings cost the most $A \$ 40 M$ in terms of process initial capital cost. Therefore due to this high initial capital cost, Concept 3 was not considered by the client as the client is very sensitive to initial capital cost. Both Concepts 1 and 2 showed very similar initial capital cost. The operating costs for the process items are more expensive for the in-line polymer concept, due to the ongoing polymer costs.

\subsection{Comparison of water balances}

The water balances indicated that the in-line polymer addition concept may offer an annual water saving benefit over the traditional cell deposition arrangement. The major influences on the water balance are the evaporation and the balance of the pond, wet, drying and dry beach areas as well as the saturation level and in situ density of the tailings.

A summary of the total calculated water return for each option is presented in Table 3.

Table 3 Summary of total water return

\begin{tabular}{cc}
\hline Tailings management option & Total water return $\left(\mathrm{m}^{3} /\right.$ year $)$ \\
\hline Concept 1 & 2177000 \\
Concept 2 & 4393000 \\
\hline
\end{tabular}

\subsection{Water saving benefits}

The water balance calculations indicate that Concept 2 provides a larger amount of water saving than Concept 1 . It is also expected that filtered tailings may provide larger water saving benefits than the other two concepts advanced for this study, however, due to the high capital cost, Concept 3 was not considered 
for further study.

As indicated by the water balance calculations, the in-line polymer addition concepts offers the potential for high water return values. The total estimated costs have been adjusted to account for the water saving benefits.

Table 4 Cost estimate summary (adjusted for water saving benefits)

\begin{tabular}{ccc}
\hline $\begin{array}{c}\text { Tailings management } \\
\text { options }\end{array}$ & $\begin{array}{c}\text { Estimated total cost }(\$ M, \\
\text { excluding GST) }\end{array}$ & $\begin{array}{c}\text { Estimated total cost adjusted for water saving benefits } \\
\text { (using perimeter discharge as reference point) }\end{array}$ \\
\hline Concept 1 & $\$ 244 \mathrm{M}$ & $\$ 244 \mathrm{M}$ \\
Concept 2 & $\$ 517 \mathrm{M}$ & $\$ 361 \mathrm{M}$ \\
\hline
\end{tabular}

The assessment shows that the in-line polymer addition concept is an expensive option based on the total costs including the water benefit. Future assessment should also consider the net present cost of each option by discounting the operational, water saving and deferred capital cost for each option.

\section{$4 \quad$ Test work phase}

\subsection{Background}

The site's magnetite tailings thickener throughput was increased by around 60\% from 200 to $324 \mathrm{t} / \mathrm{h}$ for their expansion project. A test program was completed to look at the impact of this throughput increase on the in-line polymer process. From the original thickening test report, it was mentioned that the underflow density decreased significantly with any increase in solids throughput. The high rate thickener underflow solids concentrations dropped from 51 to $48 \%(\mathrm{w} / \mathrm{w})$ solids when the flux in the thickener was increased from 0.16 to $0.28 \mathrm{t} / \mathrm{m}^{2} / \mathrm{h}$. Based on this original information, and assuming a linear relationship, for the proposed tonnage of $324 \mathrm{t} / \mathrm{h}$, equivalent to a flux of $0.34 \mathrm{t} / \mathrm{m}^{2} / \mathrm{h}$, the thickener underflow solids concentration would be expected to drop further to approximately $46 \%$ solids.

In addition to the original thickening testwork, some operating data was obtained from the magnetite thickener in 2011. In general, the daily average underflow of the thickener was around $49 \sim 51 \mathrm{wt} \%$ solids concentration. However, on certain days, the underflow solids content decreased to $45 \%$ solids. This occurred without any change in the flux of the thickener, which remained roughly constant at $0.16 \mathrm{t} / \mathrm{m}^{2} / \mathrm{h}$. This low underflow solids concentration indicated that the performance of the thickener in real operating conditions may be lower in comparison to the laboratory results.

Based on the operational data collected in 2011 the expected magnetite thickener's underflow solids concentrations with the additional increase in throughput to $324 \mathrm{t} / \mathrm{h}$ would decrease further, somewhere between 35 to $42 \%$ solids. After the thickener, the tailings will go to the existing in-line polymer addition tailings management system and discharge into the tailings storage facility.

The objective of the test work phase is to obtain sufficient information to conduct a cost and benefit analysis for an in-line polymer addition application for magnetite tailings. The mine site currently uses polymer $\mathrm{A}$ to dose the magnetite tailings. And the dosage of the polymer is $300 \mathrm{~g} / \mathrm{t}$ of dry solids. The solids concentration of the tailings slurry is one of the factors that affect the optimum dose, and the expected drop in solids concentration with an increase in throughput may result in a different optimum dose.

\subsection{Shear regime}

One of the important factors that needs to be tested is the shear regime. Polymers are sensitive to shear. The water recovery from tailings treated with polymers varies in relation to the shear rate on the tailings (Revington et al., 2012). Based on the site observations of tailings flow and deposition, the following processes would likely be occurring: 
- Initial mixing following polymer addition at the end of the spigots and at the conveyor belt. A conveyor belt was used as erosion protection.

- Further mixing and shearing in the plunge pool at the base of the conveyor belt.

- Further shearing during the flow down the steeper portion of the beach.

- The shearing continues until the polymer loses its effectiveness, and a flatter beach slop develops.

Two primary shear conditions on the beach were identified:

- Partially sheared, representing the steeper portion of the beach close to the plunge pool.

- Fully sheared, representing the flatter portion of the beach closer to the supernatant pond and decant (the remainder of the beach).

To identify a partially sheared test condition, we have estimated the shear rate based on open channel analogy. In terms of testing, the fully sheared sample will be sheared until the yield stress drops to a residual level. For the partially sheared sample, the sample will be sheared at the calculated shear rate for a selected amount of time.

\subsection{Water measurement}

Free water is decanted off the sample after mixing with polymers. The free water on top of the sample is decanted at the following intervals:

- After 10 minutes.

- After 30 minutes.

- After 24 hours.

- After 48 hours.

The results are presented as net water recovery, calculated using the equation below.

$$
\text { Net water recovery } \%=\frac{\text { water recovered-water added in polymer solution }}{\text { water in slurry }} \times 100
$$

\subsection{Testing matrix}

On the basis of a current polymer dose of $300 \mathrm{~g} / \mathrm{t}$ for the magnetite tailing, the resulting test matrix comprising a total of 24 different test conditions is presented in Table 5.

Table 5 Testing matrix

\begin{tabular}{cccc}
\hline $\begin{array}{c}\text { Solids concentration } \\
\text { (w/w\%) }\end{array}$ & $\begin{array}{c}\text { 15\% lower than current } \\
\text { dose }\end{array}$ & Current dose & 15\% higher than current dose \\
\hline 32 & Fully/partially sheared & Fully/partially sheared & Fully/partially sheared \\
35 & Fully/partially sheared & Fully/partially sheared & Fully/partially sheared \\
38 & Fully/partially sheared & Fully/partially sheared & Fully/partially sheared \\
41 & Fully/partially sheared & Fully/partially sheared & Fully/partially sheared \\
\hline
\end{tabular}

\subsection{Results}

In summary, the results show a general trend of increasing water recovery with decreasing solids concentration, in both the partially sheared and fully sheared tests (Figure 5, Figure 6). This is expected, as there is less water available for release in the higher solids concentration slurries, and this water release will be slower. However, for the higher solids concentration slurries, more water will be recovered at the thickener, making that water less susceptible to seepage and evaporation losses.

Typical flocculation result for the polymer on the magnetite tailings samples is shown here: 


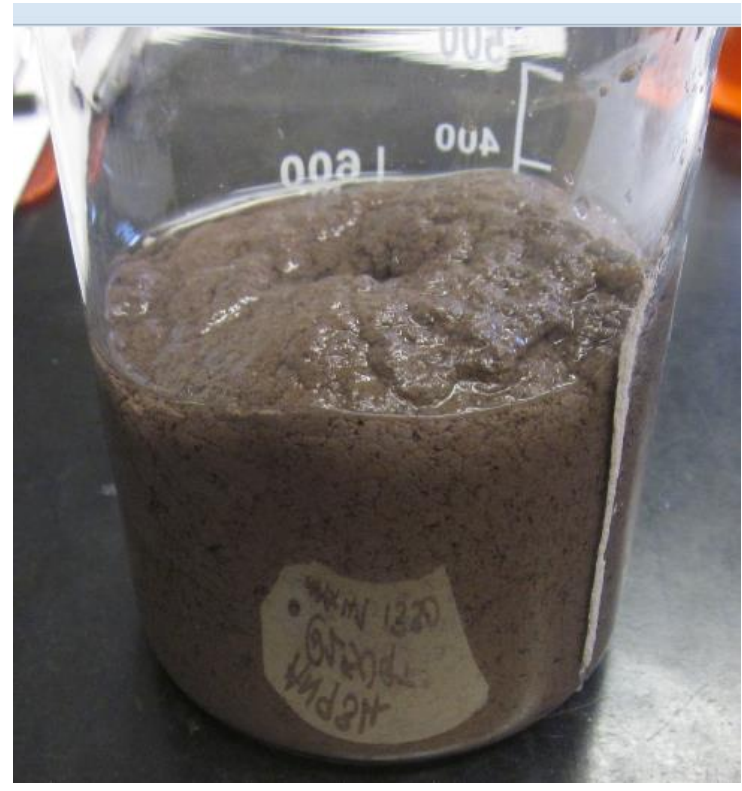

Figure 4 Typical flocculation result

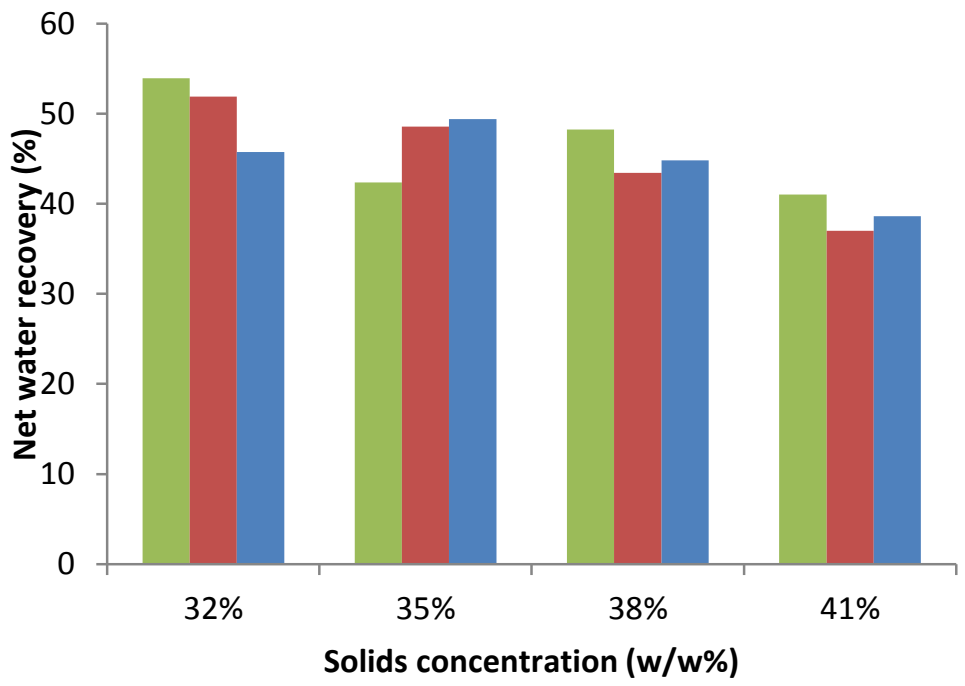

$255 \mathrm{~g} / \mathrm{t}$

- $300 \mathrm{~g} / \mathrm{t}$

$345 \mathrm{~g} / \mathrm{t}$

Figure 5 Fully sheared net water recovery after $\mathbf{4 8}$ hours

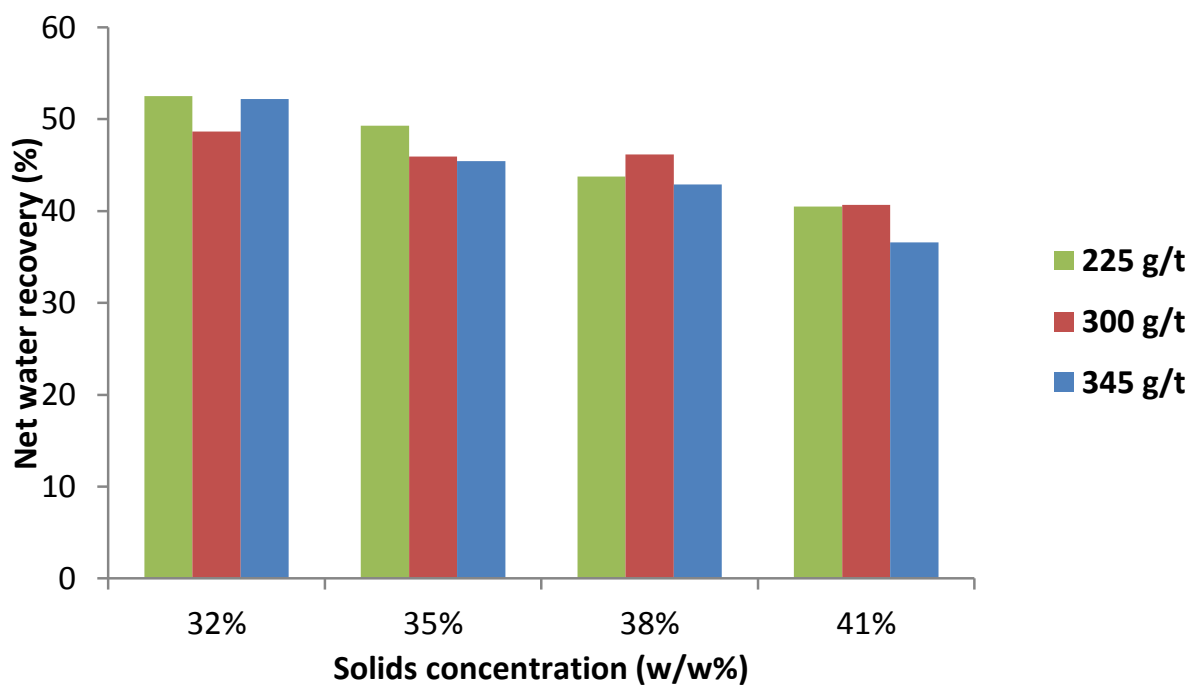

Figure 6 Partially sheared net water recovery af $\mathbf{4 8}$ hours 
Figure 7 shows that the net water recovery after 48 hours is largely similar irrespective of the dose and shearing conditions, within the ranges tested.

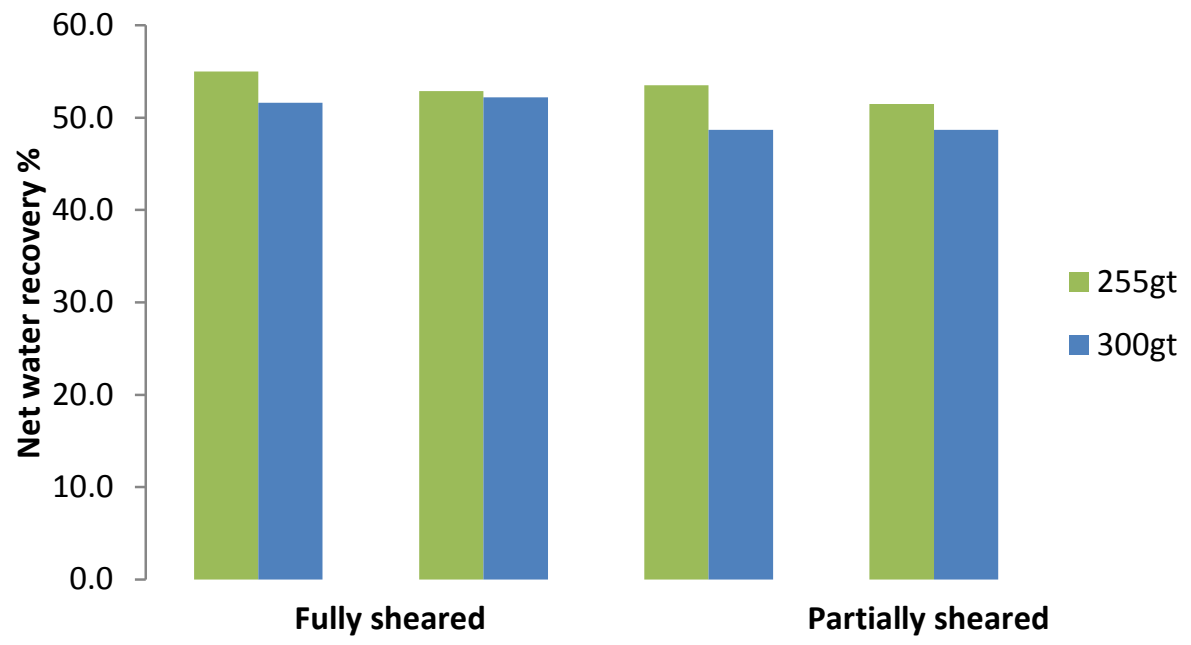

Figure 7 Fully sheared and partially sheared net water recovery for $\mathbf{3 2} \%$ solids sample at $\mathbf{4 8}$ hours

Figure 8 presents the water recovery over time as a percentage of the normalized total water recovery. Approximately 90 to $98 \%$ of the total water recovery occurred in the first 24 hours of the test. Water was released at a faster rate at the lower solids concentration e.g. in the first 30 minutes, approximately $75 \sim 87 \%$ of total water is recovered from the $32 \%$ solids sample whereas only $32 \sim 60 \%$ of total water is recovered from the $41 \%$ solids sample. The tailings with no polymer added released water at a steadier rate over the course of the test.

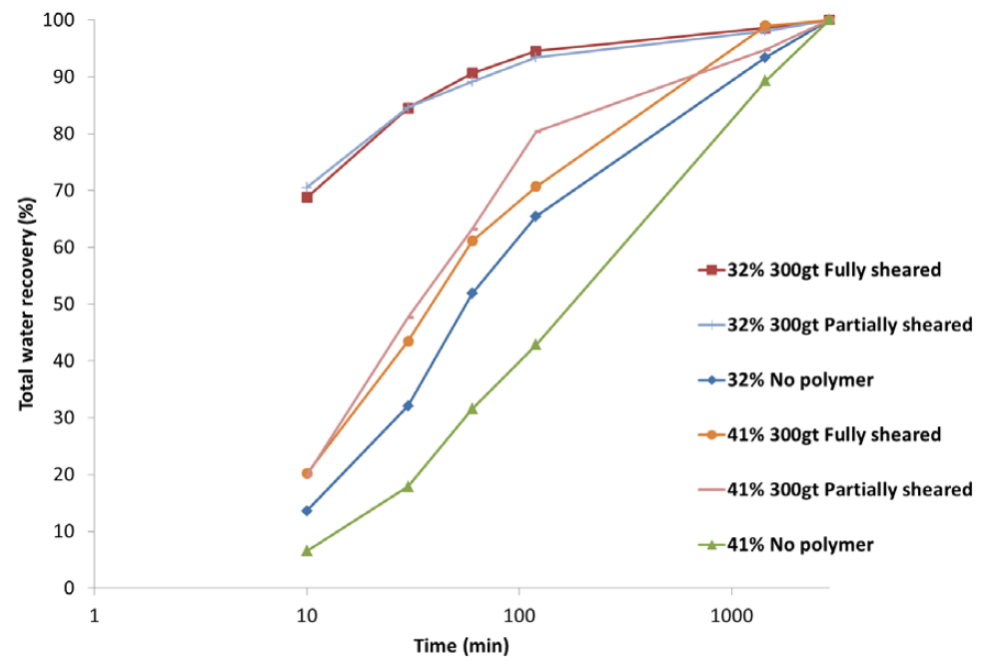

Figure 8 Time lapse total water recovery for $32 \% \mathrm{w} / \mathrm{w}$ solids concentration and $41 \% \mathrm{w} / \mathrm{w}$ solds concentration

During the test, it was observed that the turbidity of the water recovered varied, with a general decrease in turbidity (improved clarity) with increasing polymer dose.

\subsection{Summary}

Based on the test work completed, it is concluded:

- There is a general trend of increasing water recovery with decreasing solids concentration, in both fully sheared and partially sheared tests.

- Varying the polymer dose and shear regime affects the initial water recovery, up to around 2 hours after mixing and shearing. At the end of the test (48 hours) the dose and shear regime had less effect 
on the water recovery (within the range tested).

- A majority of the water release occurred in the first 24 hour period. In general, approximately 94 to $98 \%$ of the total water recovery occurred in the first 24 hours following polymer dosing.

- Based on the test work, a dose of $255 \mathrm{~g} / \mathrm{t}$ would be suitable for the new thickener throughput.

\section{Conclusion}

The paper concludes with the following findings:

- In terms of cost, the in-line polymer addition concept has a similar initial processing capital cost in comparison to a traditional slurry surface disposal concept.

- The ongoing operating cost for in-line polymer addition concept is relatively high due to polymer consumption.

- In-line polymer concept does offer potentially high water return values.

- There is a general trend of increasing water recovery with decreasing solids concentration.

- Varying the polymer dose and shear regime affects the initial water recovery, up to around 2 hours after mixing and shearing.

- At the end of the test (48 hours) the dose and shear regime had less effect on the water recovery within the range tested.

- The majority of the water release occurred in the first 24 hour period.

The in-line polymer addition tailings management method may be expensive in certain circumstances, however, the benefit of accelerating and increasing overall water release provides some unique opportunities for sites to explore.

\section{References}

Guang, R., Tshibang, M., Loayza, C. 2014, 'Application of in-line polymer addition for tailings disposal in Australia-learning and challenges', 17th International Seminar on Paste and Thickened Tailings, Australian Centre for Geomechanics, Perth.

Revington, A., Sanchez, A., Wells, P. 2012, 'Principles of TRO high density flocculation using a pipe reactor', 15th International Seminar on Paste and Thickened Tailings, Australian Centre for Geomechanics, Perth. 